\title{
Uma Fotografia da Educação Médica no Brasil
}

NOGUEIRA, Maria Inês.

Retratos da formação médica nos novos cenários de prática.

São Paulo: Hucitec, 2013. 157p.

\section{| ${ }^{1}$ Adriana Cavalcanti Aguiar |}

1 Departamento de Planejamento e Administração em Saúde, Instituto de Medicina Social da UERJ. Rio de Janeiro-RJ, Brasil. Endereço eletrônico: adrianaaguiar@ims.uerj.br

http://dx.doi.org/10.1590/S0103-73312014000200018

Publicado em 2012, o livro Retratos da formação médica nos novos cenários de prática, de Maria Inês Nogueira, analisa "desafios da formação médica contemporânea”. A autora, médica sanitarista e docente da Universidade Federal Fluminense, antecipou em alguns meses a intensificação do debate sobre a formação em medicina, inerente às polêmicas que permeiam a mídia desde 2013 relativas à provisão de médicos para áreas historicamente desassistidas do país.

Embora já em 1988 a Constituição brasileira afirmasse em seu Artigo 200 que a "ordenação" da formação profissional em saúde caberia ao Sistema Único de Saúde (SUS), a trajetória institucional neste sentido é crivada de percalços. $\mathrm{O}$ ideal da prática liberal, pautado num contrato entre médico e paciente, com pouca ou nenhuma mediação institucional, se mantém informando currículos em escolas de medicina. Ocorre que é necessário prover o Sistema Único de Saúde (SUS), pautado em princípios como universalidade, equidade e integralidade, de profissionais aptos a estabelecerem novas relações: com o conhecimento, com usuários e familiares, com membros das equipes de saúde. Relaçooes de poder, influência da cultura, necessidade de planejamento, monitoramento e avaliações das ações de saúde emergem como temas quando novas dimensões do processo saúde-doença são trazidas à baila, superando os limites do modelo biomédico, pautado na fragmentação e na separação entre mente e corpo e entre individual e coletivo. 
Desde sua homologação, em 2001, pelo Conselho Nacional de Educação, as Diretrizes Curriculares Nacionais para Cursos de Graduação em Medicina instituíram a necessidade de oferecer aos estudantes uma variedade de experiências em diversos ambientes de prática, para além da assistência médica, englobando a promoção da saúde e a prevenção de agravos. Assim, os "novos" cenários de ensino-aprendizagem a que se reporta Maria Inês, nesta segunda década do século XXI, vêm sendo campo de inovações e de oferta de novas oportunidades para estudantes de graduação da área da saúde.

Cabe portanto, como é o caso, analisar essas experiências e avançar no seu aperfeiçoamento, entendendo que mudar de cenário não significa apenas sair do hospital de ensino para ocupar centros e postos de saúde com estudantes. É necessário questionar as premissas do processo ensino-aprendizagem para engajar os futuros profissionais no trabalho. Ninguém deseja ensinar aos futuros profissionais práticas realizadas em condições de assistência aquém das desejáveis; o desafio é educar alunos de medicina a ocuparem seu lugar de cidadãos e potenciais lideranças na construção de nosso sistema de saúde, a partir da prática planejada e supervisionada, em "cenários da vida real” (p. 17): unidades básicas de saúde, espaços comunitários, organizações, não governamentais, conforme estudado por Maria Inês. Esses vários contextos podem contribuir para a integração curricular, mediante análise das interfaces entre conhecimento das ciências básicas e a prática clínica, entre a promoção da saúde e a prevenção de doenças, entre o corpo biológico, a realidade psíquica e social de indivíduos e grupos, conforme debatido no curso estudado (além da integração entre ensino-pesquisa-extensão).

O livro é produto do pós-doutorado da autora no Instituto de Medicinal Social da Universidade do Estado do Rio de Janeiro. O referencial analítico adotado privilegiou o conceito de "estilo de pensamento", conforme proposto por Fleck ("La génesis y el desarollo de um hecho cientifico. Madri: Alianza, 1986), tendo como premissa que um estilo de pensamento baseado na "tríade mecanicismo, biologicismo, individualismo" (p. 26) teria sido difundido pelo "modelo flexneriano de organização da formação médica". No contexto atual das políticas de saúde e educação superior, a obra de Maria Inês corrobora a inadequação da separação entre ciclo "básico" e ciclo "profissional", suscitando a pergunta: o que é básico, afinal, para garantir a formação competente e ética dos futuros médicos? 
Retratos da formação médica teve como cenário do estudo a Escola de Medicina da Universidade Federal Fluminense, pioneira no Estado do Rio de Janeiro na oferta de oportunidades de estágio em Atenção Primária para estudantes, em unidades de saúde (emblemáticas) como Caramujo e Engenhoca. Adotando a etnografia, a autora aproximou-se do cotidiano da disciplina "Trabalho de Campo Supervisionado", provendo um bom exemplo da utilidade da observação participante nos estudos do currículo. $\mathrm{Na}$ disciplina oferecida pelo Instituto de Saúde da Comunidade, ao longo de seis meses, Maria Inês acompanhou grupos de alunos, aos quais não passou despercebida singularidade da própria experiência: alguns alunos entendem que o contato precoce com a população permite vivenciar que "saúde não é determinada por um único elemento" (p. 41), sendo importante "pensar e formar opinião" sobre isso. Temas tratados incluíram históricos ausentes no currículo médico, apesar de sua importância para nossa população: envelhecimento, comunicação, trabalho, inclusão de pessoas com deficiência e doenças negligenciadas (p. 51).

Respeitando a necessária reciprocidade entre ensino e aprendizagem, o tema da preceptoria está presente na obra. Maria Inês analisa a diversidade de perfis dos preceptores do Trabalho de Campo Supervisionado: oriundos de dez categorias profissionais distintas. Emergiu ainda a dependência do tutor/ supervisor para o sucesso da atividade: iniciativas de problematização podem variar, a depender da expertise do tutor, dado o menor grau de controle dos conteúdos. Um dos alunos observou: "eu acho que o professor tem mais peso nesta matéria do que em outras. As outras matérias a gente pega no livro" (p. 89). Tanta riqueza também demanda desenvolvimento de mecanismos que garantam a coesão das experiências dos grupos de alunos. O trabalho, então, reporta como se dão as reuniôes periódicas de docentes e coordenação da disciplina, que permitem avançar no aprofundamento da natureza da atuação em equipes multiprofissionais, que é um objetivo explícito dos gestores do currículo.

Inovações curriculares enfrentam suas dificuldades práticas, por exemplo, na operacionalização da interdisciplinaridade: no caso estudado disciplinas afins são oferecidas por departamentos diferentes, o que prejudica a integração (p. 88).

Um desafio conhecido para os docentes que investem na integração entre teoria e prática via trabalhos nos "novos" cenários é a avaliação da aprendizagem. Num contexto institucional habitualmente pautado por avaliações somativas 
e centradas no conteúdo, Maria Inês analisa o que cabe desenvolver como estratégias de avaliação de processos complexos, numa concepção de competência que valoriza a aprendizagem de atitudes profissionais desejáveis. A experiência estudada avança no sentido da adoção de uma multiplicidade de métodos de avaliação descritos pela autora (p. 53).

O livro Retratos da formação médica nos novos cenários de prática, como o título indica, é uma bela fotografia da aplicação prática, criativa e, como era de se esperar, marcada por algumas contradições, dos princípios que informam o debate sobre a formação em saúde no Brasil contemporâneo, e serve como interessante subsídio para problematizar os rumos do desenvolvimento docente e curricular em nosso país. 